\title{
Scanning probe microscopy and nanoindentation studies of silicon carbonitride films obtained by PECVD from hexamethyldisilazane
}

\author{
V.R. Shayapov ${ }^{1 \dagger}$, M.N. Khomyakover, ${ }^{2,3}$ Yu. M. Rumyantsev ${ }^{1}$ \\ †'shayapov@niic.nsc.ru \\ ${ }^{1}$ Nikolaev Institute of Inorganic Chemistry, Acad. Lavrentiev Ave 3, 630090, Novosibirsk, Russia \\ ${ }^{2}$ Institute of Laser Physics, Acad. Lavrentiev Ave 13/3, 630090, Novosibirsk, Russia \\ ${ }^{3}$ Novosibirsk State University, Pirogova St. 2, 630090, Novosibirsk, Russia
}

\begin{abstract}
Silicon carbonitride films were deposited by PECVD from hexamethyldisilazane. To investigate their surface and to determine the parameters of roughness, scanning probe microscopy was applied. Mechanical properties of the films (hardness, Young's modulus and elastic recovery) were studied by nanoindentation method. It has been found out that hardness and Young's modulus increase along with the growth of deposition temperature. Elastic recovery is close to $100 \%$ at low deposition temperature (lower than $250^{\circ} \mathrm{C}$ ) and decreases with the rise of synthesis temperature. The results are explained by an increase in concentration of covalent bonds and other changes in chemical and phase composition.
\end{abstract}

Keywords: PECVD, silicon carbonitride, roughness, hardness, Young's modulus.

\section{Introduction}

The paper is devoted to scanning probe microscopy (SPM) and nanoindentation (NI) studies of silicon carbonitride films, obtained by plasma enhanced chemical vapor deposition from volatile organosilicon singlesource precursor hexamethyldisilazane (HMDS). SPM gives information on surface morphology and roughness parameters, which are very important for understanding of the growth process. Furthermore, many other investigation methods (nanoindentation, optical studies, etc.) are based on SPM data. Mechanical properties of the films (hardness, Young's modulus and elastic recovery) were studied by NI method.

Silicon carbonitride $\mathrm{SiC}_{\mathrm{x}} \mathrm{N}_{\mathrm{y}}\left(\mathrm{H}_{\mathrm{z}}\right)$ films appear to be a promising material for optical and mechanical coatings, and their synthesis and investigation are in the course of development [1-3]. Organosilicon films, obtained by plasma polymerization, are considered as optical coatings on polymeric surfaces, for optical sensors etc. So in this respect, data on their roughness and hardness are very important. In our earlier publications, a variety of chemical and physical properties of PECVD $\mathrm{SiC}_{x} \mathrm{~N}_{y} \mathrm{H}_{z}$ films was presented for different parameters of the deposition process [4-8]. This work represents new data on the behavior of surface roughness, elastic recovery and hardness of the PECVD SiC $\mathrm{N}_{\mathrm{y}} \mathrm{H}_{\mathrm{z}}$ films under a wide range of deposition temperatures.

\section{Experimental}

Silicon carbonitride films were deposited in r.f. (13.56 $\mathrm{MHz}$ ) inductively coupled discharge, from the mixture of hexamethyldisilazane and helium in quartz reactor at different temperatures from 70 to $800^{\circ} \mathrm{C}$. Si (100) wafers were used as substrates. Residual air pressure in reactor was $6 \cdot 10^{-3}$
Torr. More detailed information on synthesis conditions is available in [9]. All deposition parameters, except for the temperature, were kept constant.

SPM and NI studies were performed using Nanoscan-3D system (FSI TISNCM, Russia), equipped by Berkovich diamond indentor, which can work in indentation, sclerometry and SPM modes. SPM studies were performed in a tapping mode. The frequency of the probe oscillations was kept constant during scanning. Image size was $95 \times 108 \mu \mathrm{m}$, resolution $-256 \times 256$ points, scanning steps were $370 \mathrm{~nm}$ (X axis) and $425 \mathrm{~nm}$ ( $\mathrm{Y}$ axes), and speed of scanning was $10 \mu \mathrm{m} / \mathrm{s}$. So, surface cross-sections and height histograms were obtained with Nanoscan-3D. Using height histograms, arithmetic average values of surface roughness were calculated.

Nanoindentation load-displacement curves were measured at indentation depth equal to $10-15 \%$ of film thickness. The values of thickness were determined by ellipsometry and ranged within $0.5-2.2 \mu \mathrm{m}$. The force applied to films surface was $0.5-2.5 \mathrm{mN}$. Measurements were performed 10 times for every force value to reduce signalto-noise ratio. Finally, all 10 measurements were processed using Oliver-Pharr method [10] in accordance with ISO 14577 , and values of film hardness and Young's modulus were determined with accuracy of $10 \%$.

\section{Results and discussion}

It was established earlier [5] that low-temperature films have many chemical bonds of organic nature, such as $\mathrm{Si}-\left(\mathrm{CH}_{3}\right)_{n}(\mathrm{n}=1,2,3)$ fragments. Results of combustion elemental analysis for the sample, deposited at $70^{\circ} \mathrm{C}$, give mean coordination number $\bar{r}=2.23$, which is specific for «polymeric glasses» [11-13]. All these data allow concluding 


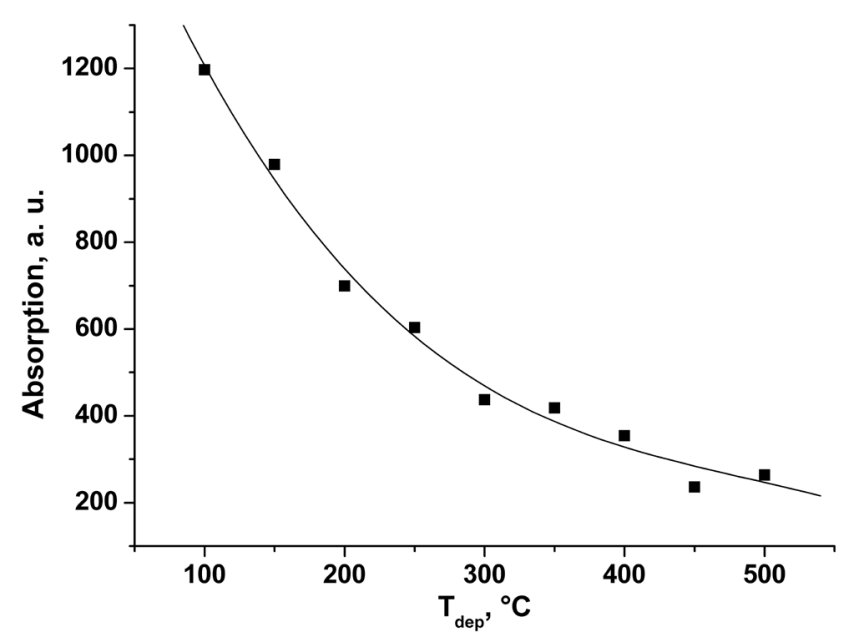

Fig. 1. Evolution of the $\mathrm{Si}-\left(\mathrm{CH}_{3}\right)_{\mathrm{n}}(\mathrm{n}=1,2,3)$. IR absorption peak at $1250-1260 \mathrm{~cm}^{-1}$ with deposition temperature rise.

that low temperature films are organosilicon plasma polymer films $[14,15]$. Concentration of hydrogen-containing bonds tends to decrease with the temperature rise (fig.1), and at high temperatures (more than $500^{\circ} \mathrm{C}$ ), inorganic composite $\mathrm{SiC}_{x} \mathrm{~N}_{y}$ material, containing only Si-C and $\mathrm{Si}-\mathrm{N}$ bonds, is formed $[4,5]$. For the film deposited at temperature of $500^{\circ} \mathrm{C}$, the value $\bar{r}=3.71$ was found, and this film was classified as «amorphous solid» [11-13].

Arithmetic average roughness $R_{a}$, depending on the deposition temperature, is presented in fig.2. We can see that the roughness decreases at the rise of synthesis temperature, but all roughness values are rather small. Comparatively high roughness of low-temperature films may be due to the impact of energetic plasma particles on soft surface of the organosilicon film that leads to its roughening. At higher deposition temperatures, rigid $\mathrm{SiC}_{x} \mathrm{~N}_{y}$ material, which is more resistant to plasma treatment, is formed [5]. A. M. Wrobel et al. observed similar dependence for the films, deposited by PECVD from tris- (dimethylamino) silane [16]. The authors assumed that it was caused by an increase in mobility of filmforming precursors at the growth surface, and by an increase in cross-linking and density of the films with temperature rise.

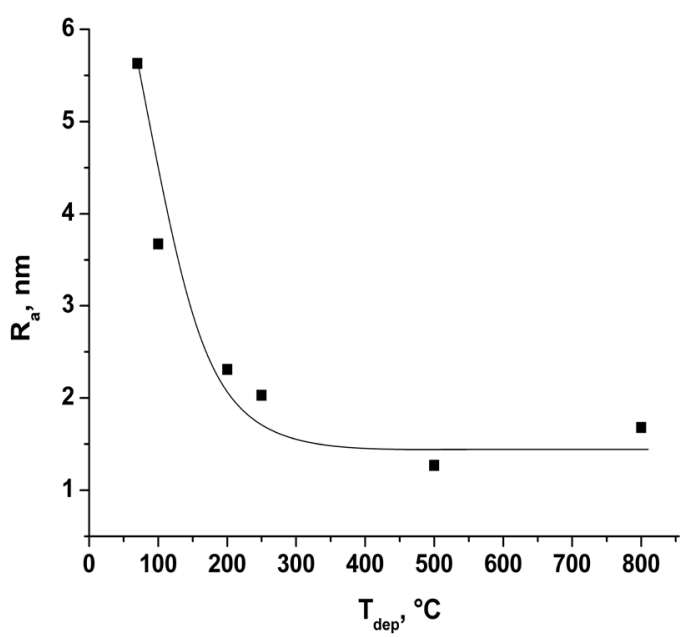

Fig. 2. Arithmetic average roughness of the $\mathrm{SiC}_{x} \mathrm{~N}_{y} \mathrm{H}_{z}$ films versus deposition temperature.

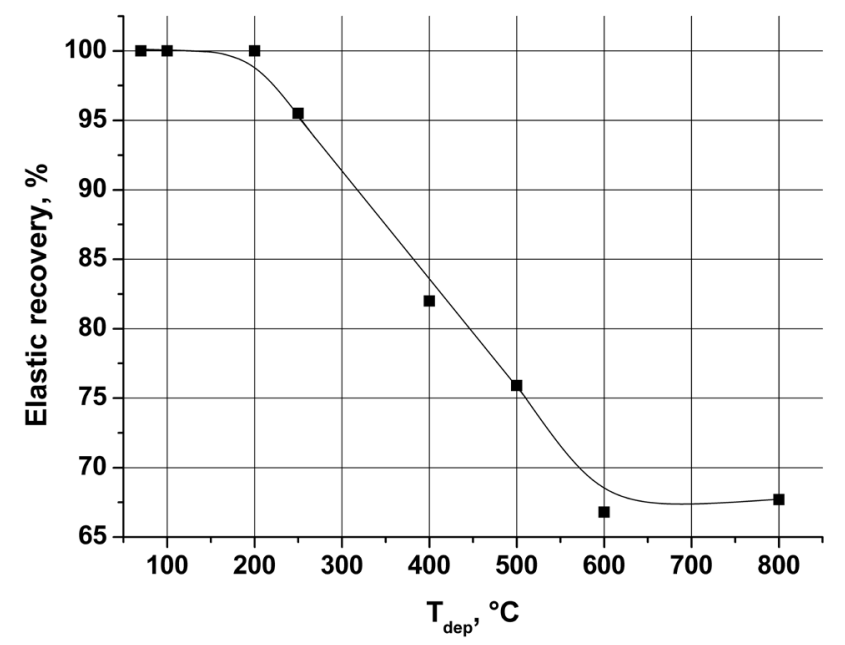

Fig. 3. Elastic recovery in $\mathrm{SiC}_{\mathrm{x}} \mathrm{N}_{\mathrm{y}} \mathrm{H}_{\mathrm{z}}$ films versus deposition temperature.

Elastic recovery gives information about relative fractions of elastic and plastic deformations. Figure 3 shows the dependence of elastic recovery of the $\mathrm{SiC}_{\mathrm{x}} \mathrm{N}_{\mathrm{y}} \mathrm{H}_{z}$ films on deposition temperature. Very high values at low deposition temperatures indicate high elasticity of the film that is in good agreement with existing conception of percolation theory [11-13] for low-coordinated materials. Note, that these films have high concentration of methyl groups and may be porous [17]. So, the observed effect is caused by poor covalent cross-linking. The opposite situation takes place at high deposition temperatures, when considerable fraction of plastic deformation was observed (fig.3). The obtained result proves our conclusion, made on the basis of stress measurements in [8]. There, we have found insensitivity of the stress to the changes of mechanical load in the synthesis temperature range of $100-400^{\circ} \mathrm{C}$.

Young's modulus and hardness of the films (fig.4a,b) significantly increase with the rise of deposition temperature. These results are also connected with the changes in chemical bonding, discussed above. Mechanical properties strongly depend on covalent bonds concentration. It is probable that insignificant changes in hardness and Young's modulus in lowtemperature region agree with mean coordination number that is lower than the percolation threshold $\bar{r}=2.4$ [11-13]. More detailed consideration of physical properties of the same samples in terms of percolation theory was presented in [7]. An additional factor at high deposition temperature is the shift of chemical composition to an increase in Si-C bond concentration [18].

Note, that NI Young's modulus is in good agreement with Surface Acoustic Waves Spectroscopy (SAWS) [19] data, obtained for the same films in [8], when deposition temperature is low. At higher temperatures, there is some discrepancy of the values. We have also obtained several values from substrate curvature (stress) measurements at temperatures $500^{\circ} \mathrm{C}$ and higher [7]. The reason for such limitation in temperature range was described in [8]. These values are lower than that obtained by NI (fig.4a). We suppose that it was plastic deformation that conditioned the difference in values. These results show significant difficulty in precise determination of Young's modulus of thin films. 

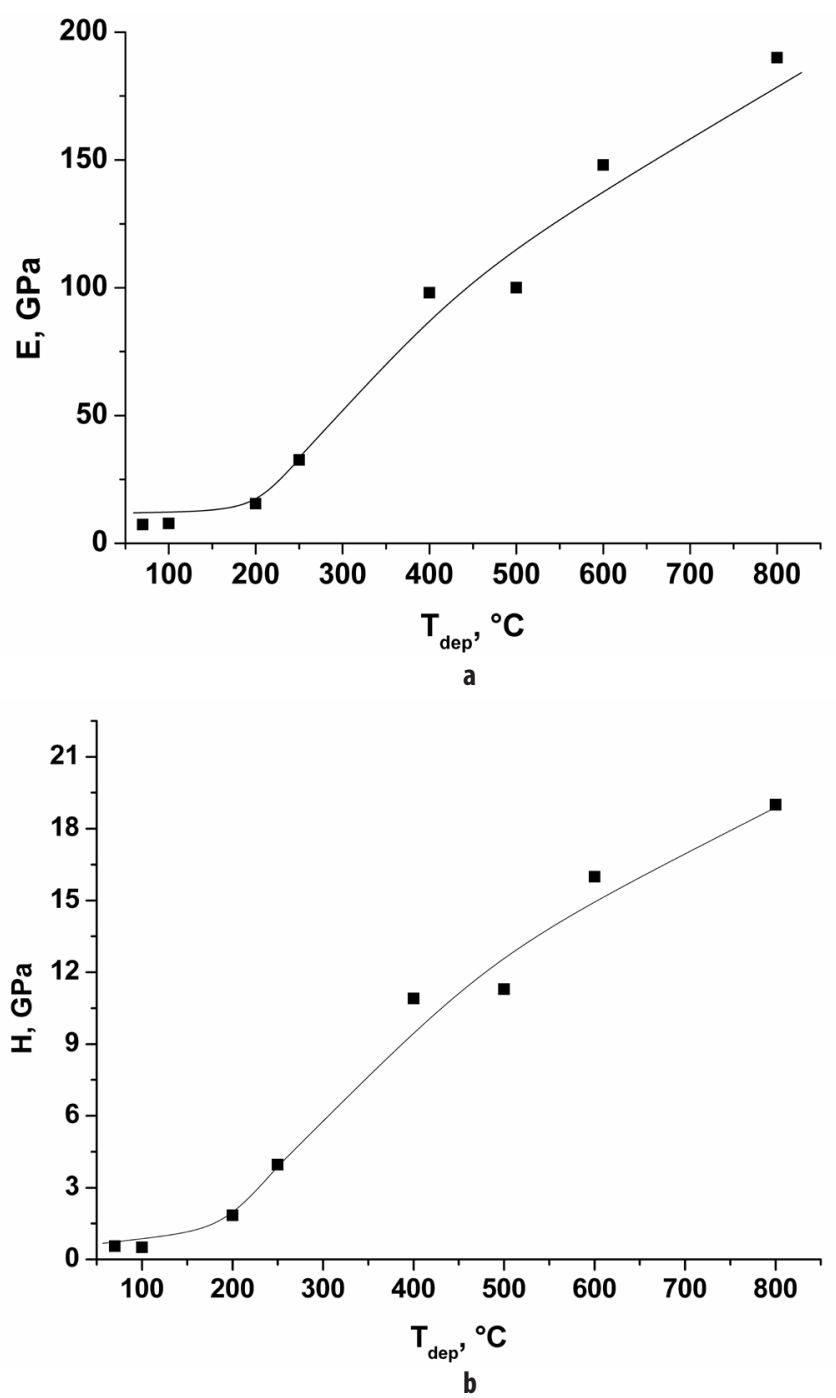

Fig. 4. Young's modulus (a) and hardness (b) of $\mathrm{SiCxNyHz}$ films versus deposition temperature.

However in general, all methods are in good agreement with each other. Problem of determining Young's modulus of thin films is well known and widely discussed in publications [2022]. We suppose that SAWS method [19] is more acceptable if properly implemented.

\section{Conclusion}

So, arithmetic average roughness and mechanical properties (hardness, Young's modulus and elastic recovery) of the $\mathrm{SiC}_{x} \mathrm{~N}_{y} \mathrm{H}_{z}$ PECVD films, deposited at various temperatures, were determined by SPM and NI methods. The behavior of roughness is most likely connected with plasma action on film surface in the reactor. Low-temperature films are easier subjected to roughening than the high-temperature ones.

Elastic recovery, a parameter that represents plastic component in deformation, is close to $100 \%$ for the films, obtained at low temperatures, that indicates high elasticity of such films. Plastic deformation tends to increase at deposition temperatures higher than $200^{\circ} \mathrm{C}$. It is explained by the characteristic change in the covalent bonds concentration at the transition through the percolation threshold, which takes place within the investigated temperature range. Hardness and Young's modulus depend on the chemical structure of the films.

This work is supported by the Russian Foundation for Basic Research Grant 12-08-31466.

\section{References}

1. Y. Peng, J. Zhou, B. Zhao, X. Tan, Zh. Zhang. Thin Solid Films. 519, 2086 (2011).

2. I. Blaszczyk-Lezak, A.M. Wrobel, T. Aoki, Y. Nakanishi, I. Kucinska, A. Tracz. Thin Solid Films. 497, 24 (2006).

3. P. Hoffmann, N. Fainer, M. Kosinova et al. Compilation on Synthesis, Characterization and Properties of Silicon and Boron Carbonitride Films, in: M. Mukherjee (Ed.), Silicon Carbide - Materials, Processing and Applications in Electronic Devices. InTech. Rijeka. (2011) p. 487-546.

4. P.S. Hoffmann, N.I. Fainer, O. Baake, M.L. Kosinova, Y. M. Rumyantsev, V. A. Trunova, A. Klein, B. Pollakowski, B. Beckhoff, W. Ensinger. Thin Solid Films. 520, 5906 (2012).

5. N. I. Fainer. Russ. J. Gen. Chem. 82, 43 (2012).

6. N.I. Fainer, M.L. Kosinova, Yu.M. Rumyantsev, E.A. Maksimovskii, F.A. Kuznetsov, V.G. Kesler, V. V. Kirienko, Han Bao-Shan, and Lu Cheng. Glass Phys. Chem. 31, 427 (2005).

7. V.R. Shayapov, Yu.M. Rumyantsev, A.A. Dzyuba, B. M. Ayupov, N. I. Fainer. Appl. Surf. Sci. 265, 385 (2013).

8. V.R. Shayapov, Yu.M. Rumyantsev, N.I. Fainer, B. M. Ayupov. Key Engineering materials. 508, 283 (2012).

9. N.I. Fainer, A.N. Golubenko, Yu.M. Rumyantsev, and E. A. Maximovskii. Glass Phys. Chem. 35, 274 (2009).

10. W. C. Oliver, G. M. Pharr. J. Mater. Res. 7, 1564 (1992).

11. H. He and M. F. Thorpe. Phys. Rev. Lett. 54, 2107 (1985).

12. M. F. Thorpe. Ann. N. Y. Acad. Sci. 484, 206 (1986).

13. B.R. Dvordjević and M.F. Thorpe. J. Phys.: Condens. Matter. 9, 1983 (1997).

14. A. M. Wrobel, M. Kryszewski. Progr. Colloid Polym. Sci. 85, 91 (1991).

15. K. W. Gerstenberg. Colloid Polym. Sci. 268, 345 (1990).

16. A. M. Wrobel. Chem. Vap. Deposition. 16, 211 (2010).

17. K.W. Gerstenberg, W. Beyer. J. Appl. Phys. 62, 1782 (1987).

18. N.I. Fainer, M.L. Kosinova, Yu.M. Rumyantsev, and F. A. Kuznetsov. J. Struct. Chem. 45 (Supplement), S65 (2004).

19. D. Schneider, T. Schwarz. Surf. Coat. Technol. 91, 136 (1997).

20. R.A. Andrievski, G. V. Kalinnikov, N. Hellgren, P. Sandstorm, D. V. Shtanskiy. Phys. Solid State. 42, 1671 (2000).

21. A. R. Shugurov, A. V. Panin, K. V. Oskomov. Phys. Solid State. 50, 1050 (2008).

22. X. Chen, J. J. Vlassak. J. Mater. Res. 16, 2974 (2001). 